\title{
Improving RAMS and WRF mesoscale forecasts over two distinct vegetation covers using an appropriate thermal roughness length parameterization
}

\author{
I. Gómez ${ }^{\mathrm{a}, *}$, V. Caselles ${ }^{\mathrm{b}}$, M.J. Estrela ${ }^{\mathrm{c}}$ \\ ${ }^{a}$ Environment and Earth Sciences Department, Faculty of Sciences, University of Alicante, Section 99, Alicante E-03080, Spain \\ ${ }^{\mathrm{b}}$ Earth Physics and Thermodynamics Department, Faculty of Physics, University of Valencia, Doctor Moliner, 50, Burjassot, Valencia 46100, Spain \\ c Geography Department, Faculty of Geography and History, University of Valencia, Avda. Blasco Ibáñez, 28, Valencia 46010, Spain
}

\section{A R T I C L E I N F O}

\section{Keywords:}

Mesoscale modelling

Land surface models

Surface energy fluxes

Thermal roughness length

Surface-layer parameterization

Numerical weather prediction/forecasting

\begin{abstract}
A B S T R A C T
Land Surface Models (LSM) have shown some difficulties to properly simulate day-time 2-m air and surface skin temperatures. This kind of models are coupled to atmospheric models in mesoscale modelling, such as the Regional Atmospheric Modeling System (RAMS) and the Weather Research and Forecasting (WRF) Model. This model coupling is used within Numerical Weather Prediction Systems (NWP) in order to forecast key physical processes for agricultural meteorology and forestry as well as in ecological modelling. The current study first evaluates the surface energy fluxes and temperatures simulated by these two state-of-the-art NWP models over two distinct vegetated covers, one corresponding to a poor and sparsely vegetated area and the other one corresponding to the tall and well-vegetated area of a forest. On the other hand, the importance of parameterizing the thermal roughness length within the LSM coupled to the corresponding atmospheric model is also evaluated. The LEAF-3 LSM is used within the RAMS modelling environment while the Noah-MP LSM is applied within WRF. Results indicate that the original version of the models underestimates the temperature during the day, more remarkably in the forested area, whereas modifications in the thermal roughness length successfully simulates the temperature and sensible heat flux forecasts over this area. This study highlights the key role of the surface exchange processes when coupling land and atmosphere models. In this regard, incorporating an extra resistance in the surface-layer parameterization through the thermal roughness length is essential to simulate well both temperatures and sensible heat fluxes, which becomes more relevant over tall and well-vegetated areas, such as a forest. This extra resistance for heat exchange prevents effective molecular diffusion in the layer between the momentum roughness length and the thermal roughness length. Additionally, an appropriate description of the canopy height permits to apply an improved surface-layer formulation over different land and vegetation covers.
\end{abstract}

\section{Introduction}

Surface energy fluxes dominate the exchange processes between the atmosphere and the earth's surface. They play a key role in vertical structure as well as in the redistribution of the heat and moisture in the atmosphere (Anurose and Subrahamanyam, 2014). In Numerical Weather Prediction (NWP) systems, the models used are not able to resolve these exchange processes due to their coarse horizontal and vertical resolutions. Therefore, parameterizing the surface heat transport process in LSM is a key point in order to accurately modelling the surface energy budget (Chen et al., 2010). These physical processes are parameterized through the known surface-layer schemes, which are mainly based on bulk aerodynamic formulations using stability functions and exchange coefficients which are empirically related to the roughness lengths for momentum, heat and moisture (Anurose and Subrahamanyam, 2013). The roughness lengths for momentum, also known as the aerodynamic roughness length, $\mathrm{z}_{0}$, is the height at which the extrapolated wind speed following the similarity theory vanishes. On the other hand, roughness lengths for heat, also known as the thermal roughness length, $\mathrm{z}_{\mathrm{Oh}}$, is the height at which the extrapolated air temperature is identical to the surface skin temperature (Yang et al., 2008).

Some formulations for $\mathrm{z}_{0}$ and $\mathrm{z}_{\mathrm{Oh}}$, used an identical treatment for both roughness lengths (Louis, 1979; Garratt, 1992), but the transport of momentum is in part related to turbulent drag due to roughness obstacles, whereas this is not the case for heat transfer (Verhoef et al., 1997). Therefore, in general, the thermal roughness length, $\mathrm{z}_{0 \mathrm{~h}}$, is assumed to be different from $\mathrm{z}_{0}$ (Beljaars and Holtslag, 1991), but is

\footnotetext{
* Corresponding author.

E-mail address: igor.gomez@ua.es (I. Gómez).
} 


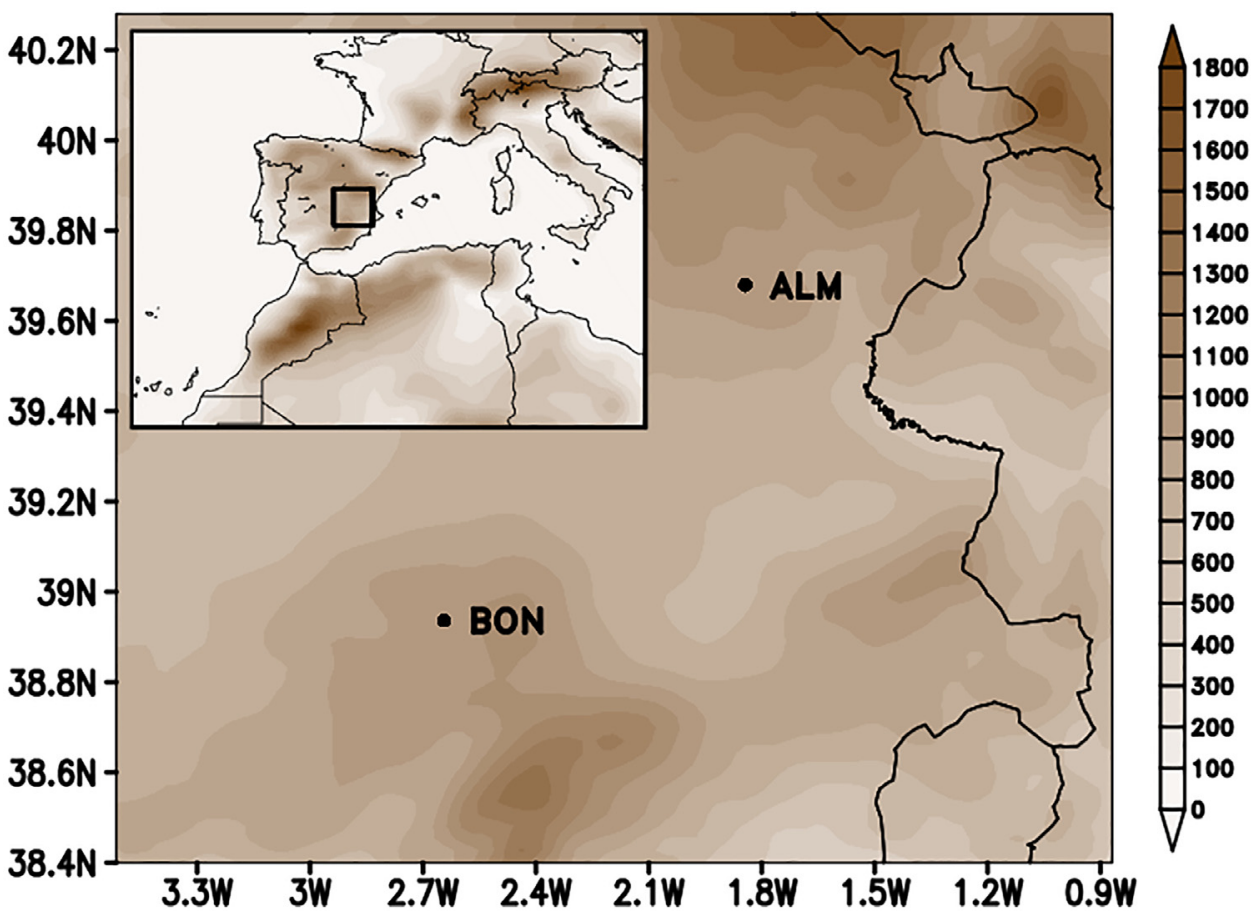

Fig. 1. Location of Almodóvar del Pinar (ALM) and El Bonillo (BON) FLUXNET stations within the finer simulation domain (D3) combined with orography (m).

derived from the roughness length for momentum in NWP models, based on the $\mathrm{kB}^{-1}$ parameter, defined as $\ln \left(\mathrm{z}_{0} / \mathrm{z}_{\mathrm{Oh}}\right)$. Different formulations for $\mathrm{kB}^{-1}$ have been proposed (see e.g. Beljaars and Holtslag, 1991; Garratt, 1992; Zilitinkevich, 1995; Verhoef et al., 1997; Sun, 1999; Yang et al., 2008; Kalverla et al., 2016). Comparing the momentum and heat roughness length ratio, Garratt (1992) recommended $\mathrm{kB}^{-1}$ values of 2 over homogeneously vegetated surfaces for practical applications. Verhoef et al. (1997) found $\mathrm{kB}^{-1}$ values of 8 and 12 for vineyard and savannah sparsely vegetated surfaces, respectively, while a small and negative value of -0.9 was found for a bare soil surface. Additionally, Stewart et al. (1994) found that $\mathrm{kB}^{-1}$ varied between 3.5 and 12.5 for the individual sites, with an average value of 4.5 over a bare soil surface. The momentum or aerodynamic roughness length can be estimated considering the geometry, morphology and heterogeneity of the corresponding surface (Brutsaert, 1975). Therefore, $\mathrm{kB}^{-1}$ depends on the underlying surface features (Mahrt, 1996).

The current study focuses on different aspects. Firstly, we investigate the ability of these two state-of-the-art NWP models, Regional Atmospheric Modelling System RAMS (Pielke, 2013) and Weather Research and Forecasting WRF Model (Powers et al., 2017), to forecast sensible heat fluxes. In order to procure a general picture of both models' performance, two distinct natural vegetation covers in Eastern Spain have been selected (Gómez et al., 2018a). The first site corresponds to a poor and sparsely vegetated area, where the vegetation layer covers between $10 \%$ and $50 \%$ of the surface, while the other site is located over a tall and well vegetated area. In addition to these fluxes, the temperature field is inspected here for these two distinct vegetation covers. The comparison of these mesoscale models in the current study show similar general trends to those obtained over a grass vegetation field in the Netherlands (Steeneveld et al., 2011). Secondly, the comparison of both RAMS and WRF is performed based on different atmospheric conditions typical of Eastern Spain during summer. Finally, we evaluate the sensitivity of these mesoscale models to the surfacelayer parameterization through a differential treatment of the momentum and thermal roughness lengths. Biases in the temperature field and the sensible heat flux found in previous studies over forested areas (Gómez et al., 2018a) could indicate that the heat transfer resistance, which is related to both $\mathrm{z}_{0}$ and $\mathrm{z}_{0 \mathrm{~h}}$, is not properly represented in models (Chen et al., 2010). The use of distinct approximations for the parameterization of the different roughness lengths affects the estimation of the turbulent fluxes at the surface and could also cause significant changes in the vertical structure of temperature within the Atmospheric Boundary Layer (ABL). Therefore, several approaches, following previous studies (see e. g. Yang et al., 2008; Chen and Zhang, 2009; Chen et al., 2010; Kalverla et al., 2016), are proposed within the RAMS and WRF modelling environments for the differential treatment of the momentum and thermal roughness lengths adopted in the current study.

The aim of the current work is then twofold. On the one hand, to compare the performance of both RAMS and WRF atmospheric models considering short-term forecasts of surface sensible heat fluxes and temperature fields over distinct land and vegetation covers. On the other hand, to assess the sensitivity of these models to the parameterization of $\mathrm{z}_{0 \mathrm{~h}}$ implemented in different LSM models coupled to RAMS and WRF with the aim of evaluating possible improvements in the RAMS and WRF mesoscale forecasts.

The paper is organised as follows. Section 2 presents the methodology and datasets used. A detailed description of the modelling strategy and experimental design is provided in this section as well. Section 3 is devoted to the simulation results and their discussion. Finally, conclusions and some final remarks are drawn in Section 4.

\section{Datasets and methodology}

\subsection{Observational and modelling datasets}

Data from two anchor FLUXNET stations, located over Almodóvar del Pinar (ALM) and El Bonillo (BON), are used in the models' assessment (see Fig. 1). In both cases, hourly measures of 2 -m temperature and surface sensible heat fluxes are used in the evaluation process. Sensible heat fluxes were measured at 18 and $13 \mathrm{~m}$ height over ALM and BON, approximately at 6 and $4 \mathrm{~m}$ above the canopy, respectively. Additionally, these fluxes were averaged every $30 \mathrm{~min}$. Accuracy of the sensible heat flux based on instrumentation available at both stations (CSAT3 sonic anemometer by Campbell Scientific Inc., combined with the LI-7500 infrared gas analyzer, LI-COR Inc.) is around $5-10 \%$, or 
(a)

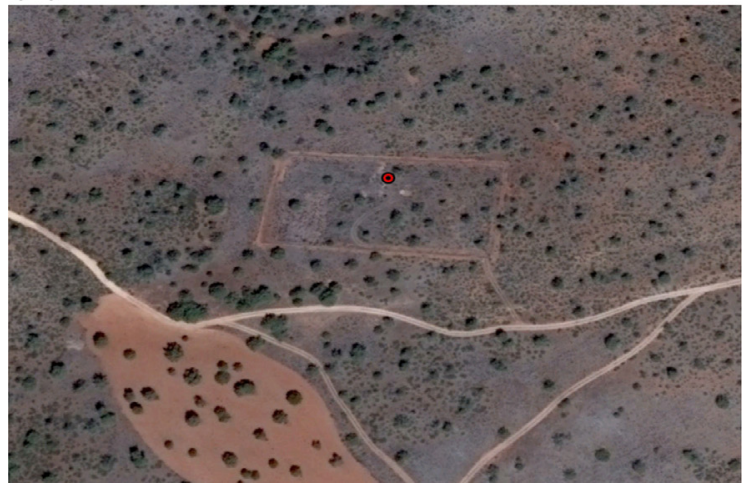

(b)

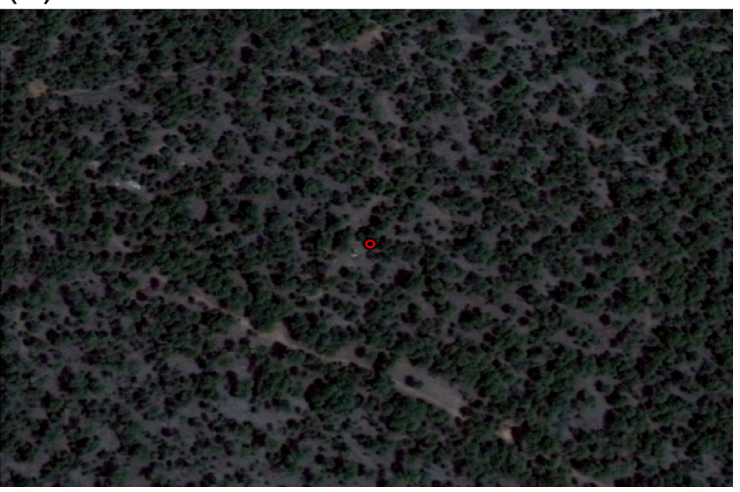

Fig. 2. Overview of the two study sites together with the corresponding FLUXNET station location: BON (a) and ALM (b).

10-20 $\mathrm{W} \mathrm{m}^{-2}$ (Mauder et al., 2006). BON site represents one of the main semi-arid Spanish juniper distributions. Considering this area, Quercus ilex are found in the best soils while J. thurifera forms grow on the more adverse soils. The surface sensible heat fluxes are measured in a mature woodland, which is characterized by a low density of juniper trees, growing in shallow stony soils (Fig. 2a). The dominant soil type over BON is Lithic leptosol (FAO, 1988). On the other hand, ALM site is located $1 \mathrm{~km}$ apart from the municipality of Almodóvar del Pinar, in the mountain range of Cuenca (central-eastern Spain). ALM is located in a forest called "Dehesa de Abajo" (Fig. 2b). It is dominated by a natural uneven-aged mixed forest, which surrounds an area of 4430 ha., approximately. ALM presents a rather homogeneous composition and structure, mainly consisting of a dominant canopy tree layer of Pinus pinaster Ait. subsp. mesogeensis (Mediterranean Maritime pine), with a subdominant tree layer of Quercus ilex L. subsp. Ballota (Holm oak). Shrub species composition includes Rosmarinus officinalis L., Thymus vulgaris L., Lavandula latifolia L. Quercus coccifera, and Genista scorpius L. The dominant soil type over ALM is Lithic Leptosol, associated with Chromic Luvisol (FAO, 1988; López-Serrano et al., 2016).

On the other hand, the Land Surface Temperature (LST; Caselles et al., 1997; Trigo et al., 2008) generated by the Land Surface Analysis Satellite Applications Facility (LSA SAF) from satellite data, obtained from the Meteosat Second Generation (MSG) Spinning Enhanced Visible and Infrared Imager (SEVIRI) (MSG-SEVIRI), is used as well for the models' assessment in the current study (Gómez et al., 2016b, 2018b,c).

\subsection{Model configurations: General settings}

Two state-of-the-art NWP models, widely used by researchers and operational forecasters, have been selected to simulate the forecasting period: RAMS model (Cotton et al., 2003; Pielke, 2013), version 6.0, and the Advanced Research core of the WRF model (WRF-ARW; Skamarock et al., 2008), version 3.6.1. RAMS and WRF have been configured using three nested domains of $48 \mathrm{~km}, 12 \mathrm{~km}$ and $3 \mathrm{~km}$ horizontal resolution, respectively. In the vertical, a total of 45 levels have been selected for both models, with 24 levels in the lowest $2000 \mathrm{~m}$ and 9 levels in the lowest $300 \mathrm{~m}$ within the WRF modelling framework, and 22 levels in the lowest $2000 \mathrm{~m}$ and 8 levels in the lowest $300 \mathrm{~m}$ within the RAMS modelling environment.

In terms of physical parameterizations, the Dudhia shortwave radiation (Dudhia, 1989) and the rapid radiative transfer model (RRTM) longwave radiation (Mlawer et al., 1997) are used within WRF as radiation options, while the Chen-Cotton scheme is used for longwave and shortwave radiation (Chen and Cotton, 1983) within the RAMS framework. Additionally, the Kain-Fritsch scheme is used for convection on the two most outer grids by both WRF (Kain, 2004) and RAMS (Castro et al., 2002). On the other hand, RAMS and WRF use the YSU
PBL scheme (Hong et al., 2006; Gómez et al., 2016a). This PBL parameterization is coupled with the augmented Noah LSM, known as Noah-MP (multiparameterization options; Niu et al., 2011) in the WRF environment, and with the Land-Ecosystem Atmosphere Feedback Model (LEAF-3) in the RAMS simulations (Walko et al., 2000).

RAMS and WRF have been used to simulate the time period from 6 to 12 July 2011, which clearly distinguishes different typical summer atmospheric conditions over the study area. This simulation period is divided for the analysis of results according to the dominant atmospheric condition established over the area of study each specific day (Gómez et al., 2018a-c). In this regard, Western synoptic flow dominates the meteorological situation over this region on 6, 7 and 8 July. On the other hand, 9 and 10 July are characterized by the development of mesoscale circulations, while an Eastern synoptic flow is well established over this area on 11 July. Finally, a Western synoptic flow is once again the dominant atmospheric condition over the region of study on 12 July. However, it is accompanied with some persistence cloudiness around the study area starting around noon, even though no significant cloudiness is specifically observed over BON and ALM. As it will be seen later, both RAMS and WRF simulate cloudiness over these two locations, reflecting the difficulty of mesoscale models regarding cloud forecasting (Gómez et al., 2018b), thus producing higher errors than those obtained for instance on 6 or 7 July. RAMS and WRF have been used to perform a daily simulation with a forecast horizon of $36 \mathrm{~h}$ and a temporal resolution of $1 \mathrm{~h}$, starting at 12 UTC the previous day. In this regard, the first $12 \mathrm{~h}$ are considered as the spin-up time, and only the remaining $24 \mathrm{~h}$ (a complete day) are considered in the evaluation. Initial and boundary conditions for both RAMS and WRF are given by the NCEP FNL dataset at $1 \times 1^{\circ}$ horizontal resolution and at $6 \mathrm{~h}$ intervals.

In order to evaluate the results produced using both mesoscale models, a set of sensitivity experiments have been designed. In this regard, a total of four RAMS simulations have been performed for each individual day within the period of study. Considering all sensitivity tests performed using this model, the reference run is that provided by RAMS using a heterogeneous initialization by means of assimilating the FNL soil parameters into the model (RAMS). However, based on previous results related to the significant importance of the initial soil moisture (SM) content in the simulation (Gómez et al., 2015, 2016a, 2018a-c), the original SM has manually been reduced to the half (multiplying this parameter with a factor of 0.5). In this regard, the original SM has been found to produce very high values of this parameter, whereas the current adjustment in the initial SM field produces more realistic results (Gómez et al., 2018c). In addition, the original surface-layer scheme used in the RAMS model has been modified in order to evaluate the sensitivity of the model to land-atmosphere coupling. In this regard, three additional simulations have been performed using this model (RAMS_Z10, RAMS_Z95 and RAMS_C09; Table 1). 
Table 1

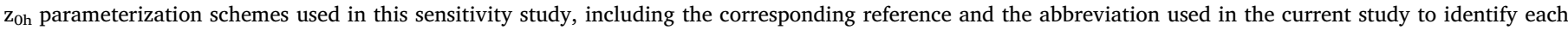
scheme simulation: $\operatorname{Re}_{*}=\mathrm{z}_{0} \mathrm{u}_{*} / v, k=0.4, v$ is the fluid kinematical viscosity and $\mathrm{h}$ is the canopy height (in meters).

\begin{tabular}{|c|c|c|c|c|}
\hline Formula & Reference & Abbreviation & RAMS & WRF \\
\hline $\mathrm{z}_{0}=\mathrm{z}_{0 \mathrm{~h}}$ & Louis (1979) & L79 & RAMS & - \\
\hline $\mathrm{z}_{0} / \mathrm{z}_{\mathrm{Oh}}=10$ & Garratt (1992) & $\mathrm{Z} 10$ & RAMS_Z10 & - \\
\hline$z_{0 h}=z_{0} \exp \left(-k C_{z i l} R e^{1 / 2}\right)$ & Zilitinkevich (1995) & Z95 & RAMS_Z95 & WRF_Z95 \\
\hline$C_{z i l}=10^{(-0.4 h)}$ & Chen and Zhang (2009) & C09 & RAMS_C09 & WRF_C09 \\
\hline$z_{0 h}=\frac{70 v}{u} \exp \left(-7.2 u^{0.5}\left(T_{0.25}\right)\right)$ & Yang et al. (2008) & Y08 & - & WRF_Y08 \\
\hline
\end{tabular}

Besides, WRF is compared with RAMS using five experiments (Table 1). WRF is initialized using the FNL soil parameters (WRF), similarly to the reference RAMS experiment (RAMS), that is, reducing the original FNL SM field to the half, similar to Kalverla et al. (2016), although they used a different operational analysis product.

\subsection{Model configurations: Modifications in the surface-layer schemes}

The surface-layer scheme is used to calculate the fluxes from the land surface into the atmosphere. For instance, the sensible heat flux, is determined using the expression:

$H=\rho C_{p} C_{h} u\left(T_{s}-T_{a}\right)$

where $\rho$ represents the air density $\left(\mathrm{kg} \mathrm{m}^{-3}\right), \mathrm{C}_{\mathrm{p}}$ is the specific heat capacity of air $\left(\mathrm{J} \mathrm{K}^{-1} \mathrm{~kg}^{-1}\right), \mathrm{C}_{\mathrm{h}}$ is the surface exchange coefficient for heat, and $\mathrm{u}$ is the wind speed at the reference height. In this regard, the sensible heat flux depends on the difference between the surface $\left(\mathrm{T}_{\mathrm{s}}\right)$ and the air $\left(\mathrm{T}_{\mathrm{a}}\right)$ temperatures as well as on the surface exchange coefficient.

Considering RAMS and WRF, the exchange coefficient for heat is calculated considering different approaches. On the one hand, the surface-layer scheme implemented in RAMS uses the corresponding analytical solution proposed by Louis (1979) (L79), which is implemented within the LEAF-3 LSM model (Walko et al., 2000). On the other hand, WRF uses the general Monin Obukhov similarity theory proposed by Brutsaert (1982) within the Noah-MP LSM model (Niu et al., 2011). The exchange coefficient for heat is calculated within the Noah-MP model itself, and therefore there is no direct communication between this LSM model and the surface-layer scheme over land surfaces (Milovac et al., 2016). For both LEAF-3 and Noah-MP LSMs, the roughness length for heat $\left(\mathrm{z}_{\mathrm{Oh}}\right)$ is assumed to be equal to the roughness length for momentum $\left(\mathrm{z}_{0}\right)$. Therefore, the reference RAMS and WRF simulations are performed with no distinction between $\mathrm{z}_{0}$ and $\mathrm{z}_{\text {Oh }}$ (Table 1).

However, different studies have emphasized the need of a critical assessment of the treatment of $\mathrm{z}_{0}$ and $\mathrm{z}_{\mathrm{Oh}}$. For instance, Anurose and Subrahamanyam $(2013,2014)$ suggested a differential approach for $z_{0 h}$ and $z_{0}$ in order to improve the original Louis scheme (L79) over heterogeneous terrain. The use of different $\mathrm{z}_{0 \mathrm{~h}}$ and $\mathrm{z}_{0}$ over rough surfaces is as well supported by experimental and theoretical evidences (see e. g. Brutsaert, 1975; Beljaars and Holtslag, 1991; Hopwood, 1995; Mahrt, 1996; Chen et al., 1997), and an identical treatment of $\mathrm{z}_{0 \mathrm{~h}}$ and $\mathrm{z}_{0}$ is only valid for very smooth surfaces (Song, 1998). Therefore, considering the heat transfer between the surface and $\mathrm{z}_{0}$, an additional resistance for heat transport should be considered so as to account for the molecular diffusion, which is a much less efficient process than turbulent transport (Kalverla et al., 2016).

In order to consider this heat resistance, the original L79 scheme has been modified in RAMS. The transfer coefficient for heat has been divided in a component related to the momentum transport and another one related to the heat transport, as follows:

$C_{h, n}^{d}=k^{2}\left\{\ln \left(\frac{z}{z_{0}}\right)\right\}^{-1}\left\{\ln \left(\frac{z}{z_{0 h}}\right)\right\}^{-1}$
Considering an additional resistance for heat transport in WRF, equation (16) in Niu et al. (2011) needs to be modified as follows in order to compute the exchange coefficient for heat:

$C_{h}^{d}=\frac{k^{2}}{\left[\ln \left(\frac{z-d_{0}}{z_{0}}\right)-\psi_{m}\left(\frac{z-d_{0}}{L}\right)\right]\left[\ln \left(\frac{z-d_{0}}{z_{0 h}}\right)-\psi_{h}\left(\frac{z-d_{0}}{L}\right)+\ln \left(\frac{z_{0}}{z_{0 h}}\right)\right]}$

A ratio $\mathrm{z}_{0} / \mathrm{z}_{0 \mathrm{~h}}=10$ is considered a good choice for homogeneous areas of bare soil and vegetation (Garratt, 1992). In contrast, higher ratios are supposed to be used for heterogeneous surfaces. For example, Hopwood (1995) suggested the ratio of $\mathrm{z}_{0}$ and $\mathrm{z}_{0 \mathrm{~h}}$ to be of about 80, while Anurose and Subrahamanyam $(2013,2014)$ proposed a ratio of 100. For the area of study, different values for the ratio $\mathrm{z}_{0} / \mathrm{z}_{0 \mathrm{~h}}$ have been tested. However, high values of this ratio produce a remarkable overestimation of the 2-m air temperature field and the sensible heat flux. A ratio of the roughness length of 10 seems to produce better results, and it has been adopted in the current work (RAMS_Z10; Table 1). Additionally, other parameterization schemes are available in the literature (see e. g. Chen et al., 1997; Yang et al., 2008; Kalverla et al., 2016). From the different parameterizations proposed to determine the roughness length ratio, two commonly used formulations are the one suggested by Zilitinkevich (1995) and that proposed by Chen and Zhang (2009). The first one relates $z_{0 h}$ to flow characteristics while Chen and Zhang (2009) relates $\mathrm{z}_{\mathrm{Oh}}$ to the canopy height. Both formulations are tested within RAMS (RAMS_Z95 and RAMS_C09, respectively) and WRF (WRF_Z95 and WRF_C09, respectively) modelling environments. Using WRF, an additional test is implemented based on the parameterization suggested by Yang et al. (2008), WRF_Y08 (Table 1).

It must be highlighted at this point that the original surface-layer schemes built into RAMS and WRF models have been modified by the authors with the aim of implementing all these mentioned formulations in the corresponding model (Table 1).

Finally, the heat transport coefficient can be computed as well in Noah-MP considering the formulation proposed by Chen et al. (1997), applying equation (15) as described in Niu et al. (2011). This parameterization has been tested in the current study (WRF_C97) using the Zilitinkevich (1995) formulation included in Table 1.

\section{Results and discussion}

RAMS_C09 produces similar results to those obtained by RAMS, RAMS Z95 and RAMS Z10 over BON in terms of the sensible heat flux (Fig. 3b). In this case, the highest difference is obtained over BON between RAMS_C09 and RAMS_Z95 under the influence of Western synoptic circulations (6-8 July). Similar results are found both over BON and ALM considering the sensible heat flux simulated by the distinct RAMS runs, with differences lower than $10-20 \mathrm{~W} \mathrm{~m}^{-2}$ both at BON and ALM. Additionally, Fig. 4b shows that WRF_C09 produces similar sensible heat flux values to WRF over BON, while more differences are observed over ALM (Fig. 4a). A general bias of 20 and $19 \mathrm{~W} \mathrm{~m}^{-2}$ is obtained over BON for WRF and WRF_C09, respectively, while a difference of $25 \mathrm{~W} \mathrm{~m}^{-2}$ is reached over ALM. In general, RAMS underestimates the sensible heat flux over ALM, as shown by the negative 

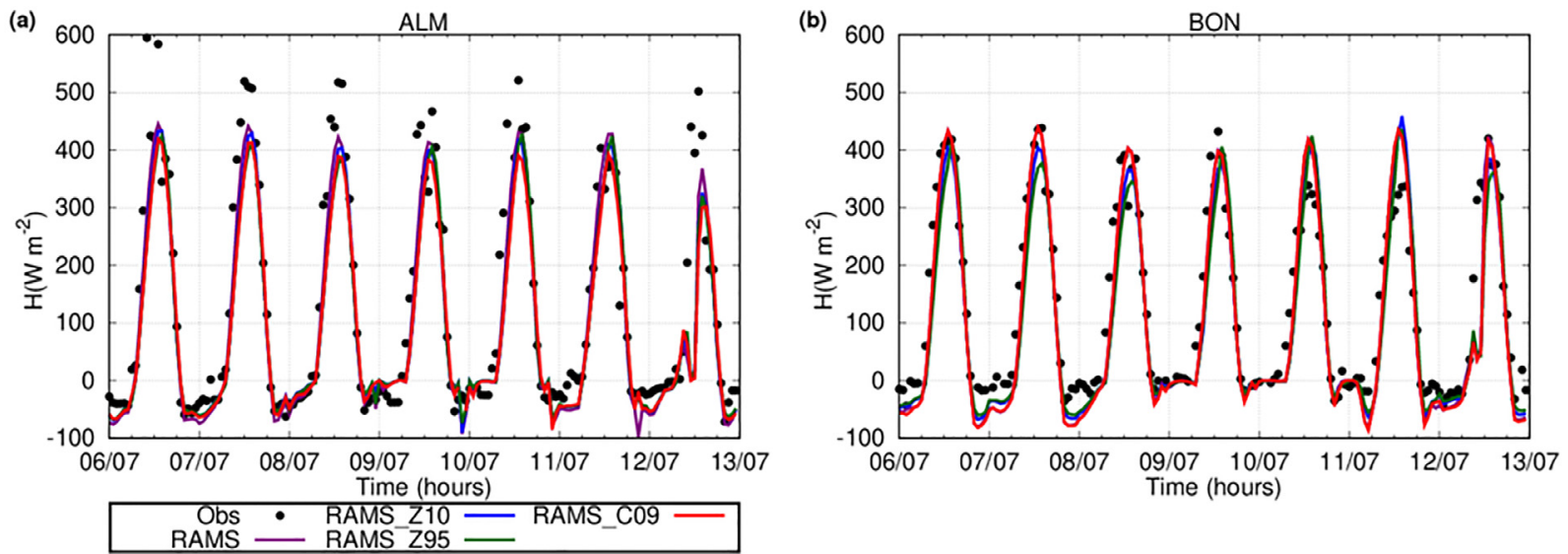

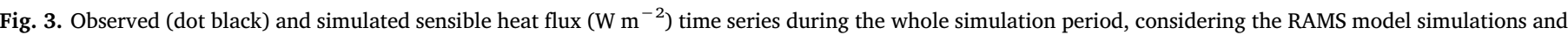
the two FLUXNET stations: ALM (a) and BON (b).

bias score included in Fig. 5. In contrast, this result is reversed under Eastern synoptic conditions. Under the cloudy Western synoptic flow, both models underestimate the observations, with WRF producing in general lower statistical scores than RAMS (Fig. 5). Over BON, a positive bias is obtained under the Eastern synoptic circulation, considering all simulations (Fig. 5c,d).

Fig. 6a shows that RAMS_C09 tends to produce higher day-time temperatures than observed over ALM. We must clarify at this point that the 2-m temperature observations are compared to 2-m temperature product derived from the RAMS and WRF simulations. In this case, differences higher than $5{ }^{\circ} \mathrm{C}$ are obtained between RAMS_C09 and RAMS. However, applying RAMS_Z10 and RAMS_Z95 remarkably improves the RAMS results over ALM, with a better agreement with in-situ observations. RAMS_Z10 over BON produces a tendency to overestimate the observations and to advance the occurrence of the maximum temperature. In this case, RAMS and RAMS_C09 produce similar results to each other, whereas both RAMS_Z10 and RAMS_Z95 reach maximum temperature too early as compared to the observations, although the latter produces a much stronger peak. On the contrary, although WRF_C09 is very similar to WRF over BON, larger differences are obtained over ALM (Fig. 7b,d). RAMS and WRF in general underestimates the observations over ALM and BON, but lower general errors are obtained using these model simulations over $\mathrm{BON}$ in comparison to those found over ALM (Fig. 8).

Additionally to the 2-m temperature, we compare the RAMS and WRF simulated skin temperature in relation to the values provided by the SEVIRI LST product (Figs. 9 and 10). RAMS follows the SEVIRI skin temperature evolution during the day over ALM (Fig. 9a). As for the 2- $\mathrm{m}$ temperature, more differences are observed between WRF and WRF_C09 over ALM than over BON (Fig. 10a). RAMS and WRF produce colder temperatures than SEVIRI over BON, but WRF produces the greatest differences in relation to SEVIRI during the day using WRF and WRF_C09. In this case, RAMS is the simulation closest to SEVIRI, even though differences up to $5{ }^{\circ} \mathrm{C}$ arises (Fig. 9b). However, the application of WRF_Z95, WRF_Y08 and WRF_C97 is able to capture the daily evolution of the LST SEVIRI over BON, with remarkable differences with respect to WRF and WRF_C09 (Fig. 10b).

It seems clear that those schemes parameterized using $\mathrm{u}_{*}$ or $\mathrm{Re}_{*}$ (which also incorporates $\mathrm{u}_{*}$ ), such as Z95, produce lower sensible heat fluxes within the WRF modelling environment than the schemes using $\mathrm{z}_{0 \mathrm{~h}}=\mathrm{z}_{0}$, such as the original WRF simulation (Fig. 4). This lower sensible heat flux simulated by WRF_Z95 in comparison to WRF is related to higher skin temperatures (Fig. 10). Considering WRF simulation, $\mathrm{z}_{\mathrm{Oh}}=\mathrm{z}_{0}$ does not include any extra resistance, since the term $\mathrm{kB}^{-1}=0$. However, by making $\mathrm{z}_{\mathrm{Oh}}$ and $\mathrm{z}_{0}$ different, an extra resistance is included in the surface-layer parameterization. Additionally, applying a weak coupling in WRF_Z95 using this extra resistance $\left(\mathrm{C}_{\mathrm{zil}}=1.0\right.$ in $\left.\mathrm{Z95}\right)$, lower $\mathrm{z}_{\mathrm{Oh}}$ and higher $\mathrm{kB}^{-1}$ than those simulated by WRF are obtained. This extra resistance leads to lower sensible heat fluxes and larger skin temperatures using WRF_Z95. Taking into account Eq. (1), the sensible heat flux is directly related to the temperature gradient between the surface skin and the air temperature of the first model level, as well as to the surface exchange coefficient for heat $\left(\mathrm{C}_{h}\right)$. No significant differences are observed in this case among the first model level temperatures simulated within the WRF modelling framework (not shown). However, differences higher than $15{ }^{\circ} \mathrm{C}$ (Fig. 10) are found for the surface skin
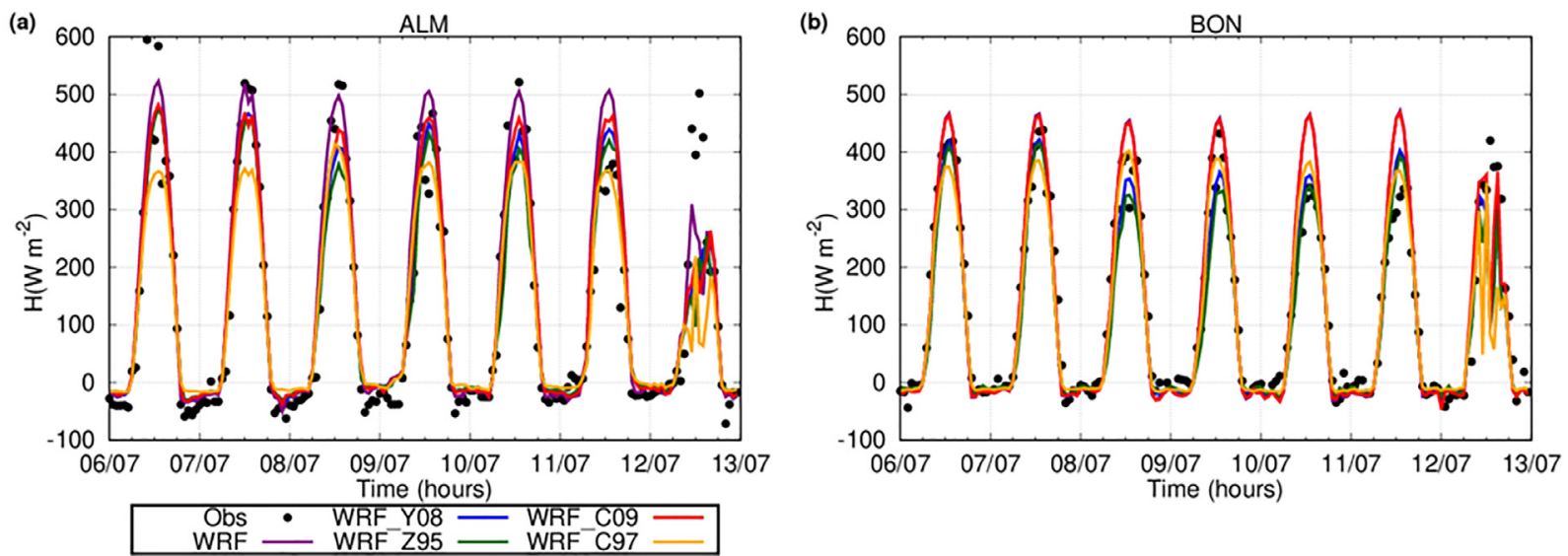

Fig. 4. Same as Fig. 3, but considering the WRF model simulations. 
(a) ALM

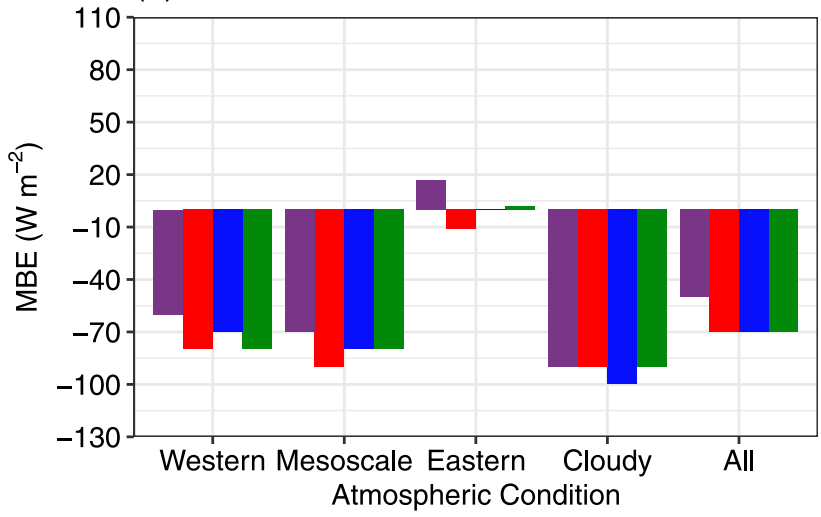

(c) BON

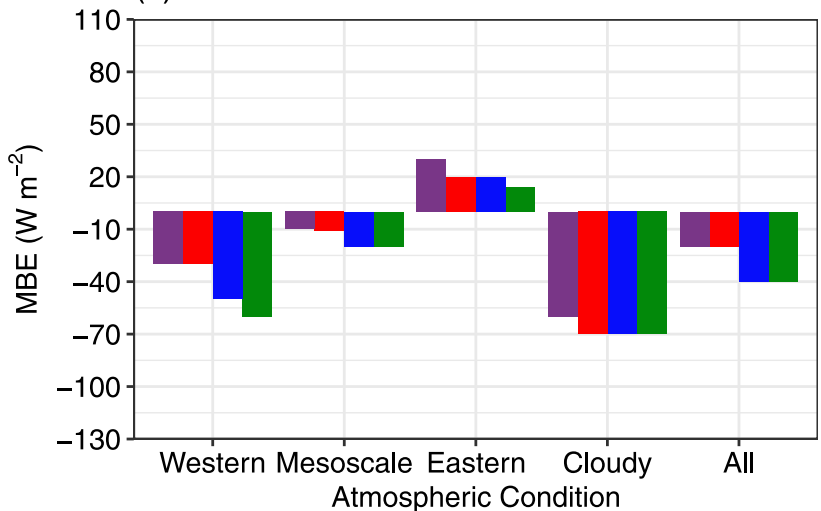

(b) ALM

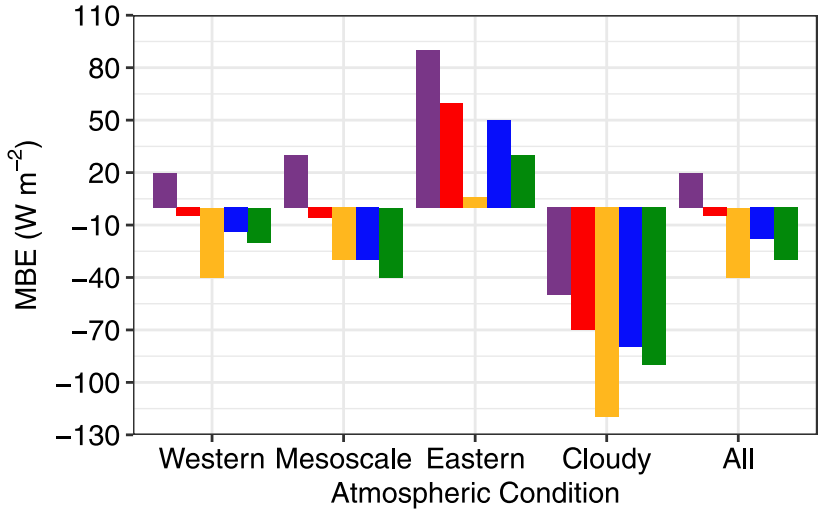

(d) BON

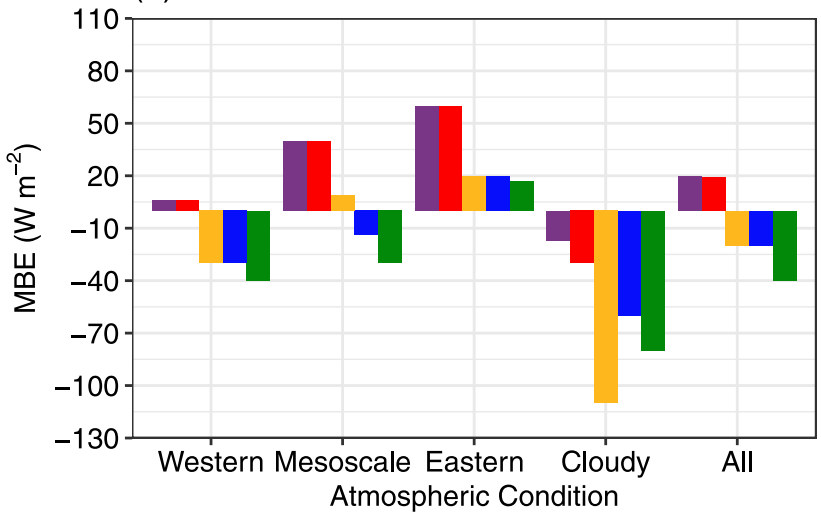

WRF WRF_C09 $\quad$ WRF_C97 $\quad$ WRF_Y08

WRF_Z9

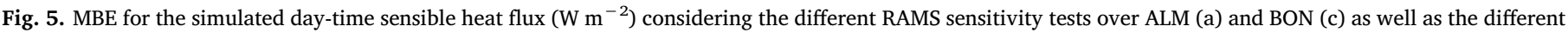
WRF sensitivity tests over ALM (b) and BON (d), under distinct atmospheric conditions.

temperature comparing WRF and WRF_Z95. A larger gradient between the surface skin temperature and the first model level air temperature should lead to higher sensible heat fluxes. However, this is not the case here. Therefore, the lower sensible heat fluxes obtained using WRF_Z95 in comparison to WRF should be related to $\mathrm{C}_{\mathrm{h}}$. Comparing this parameter for these two simulations (Fig. 11), WRF produces larger $C_{h}$ values, thus increasing the sensible heat flux. Keeping $\mathrm{z}_{\mathrm{Oh}}=\mathrm{z}_{0}$ produces an effective molecular diffusion up to $z_{0}$, but no effective molecular diffusion or turbulence appears between $\mathrm{z}_{0}$ and $\mathrm{z}_{\mathrm{Oh}}$ layer when $\mathrm{z}_{\mathrm{Oh}}<\mathrm{z}_{0}$
(Kalverla et al., 2016). The latter produces an extra resistance which is in agreement with the low sensible heat fluxes simulated by WRF_Z95, as shown in Fig. 4. The higher skin temperatures simulated by WRF_Z95 seem to be related to higher values of the simulated ground heat flux (not shown). This result should be expected since the extra resistance produced by the Z95 parameterization, as in Eq. (3) by means of the $\mathrm{kB}^{-1}$ term, would difficult the heat transfer to the atmosphere and thus increase the ground heat flux. In fact, the ground heat flux is directly related to the temperature gradient between the surface skin and
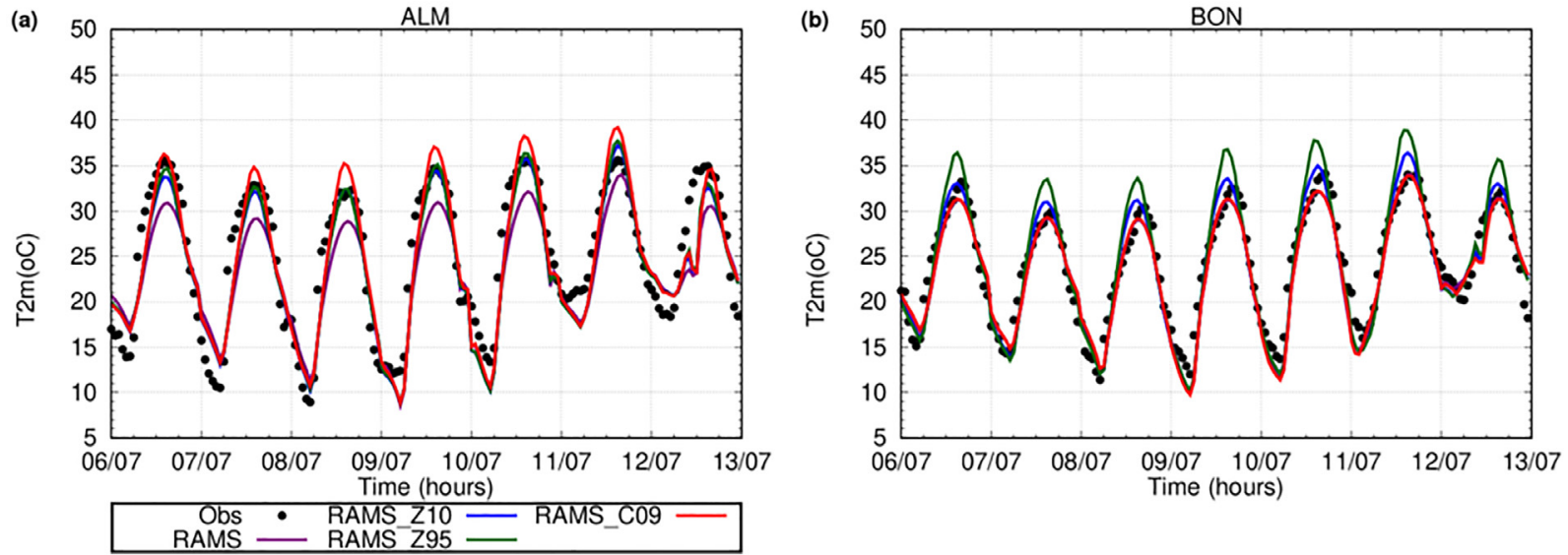

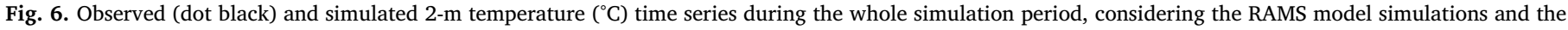
two FLUXNET stations: ALM (a) and BON (b). 

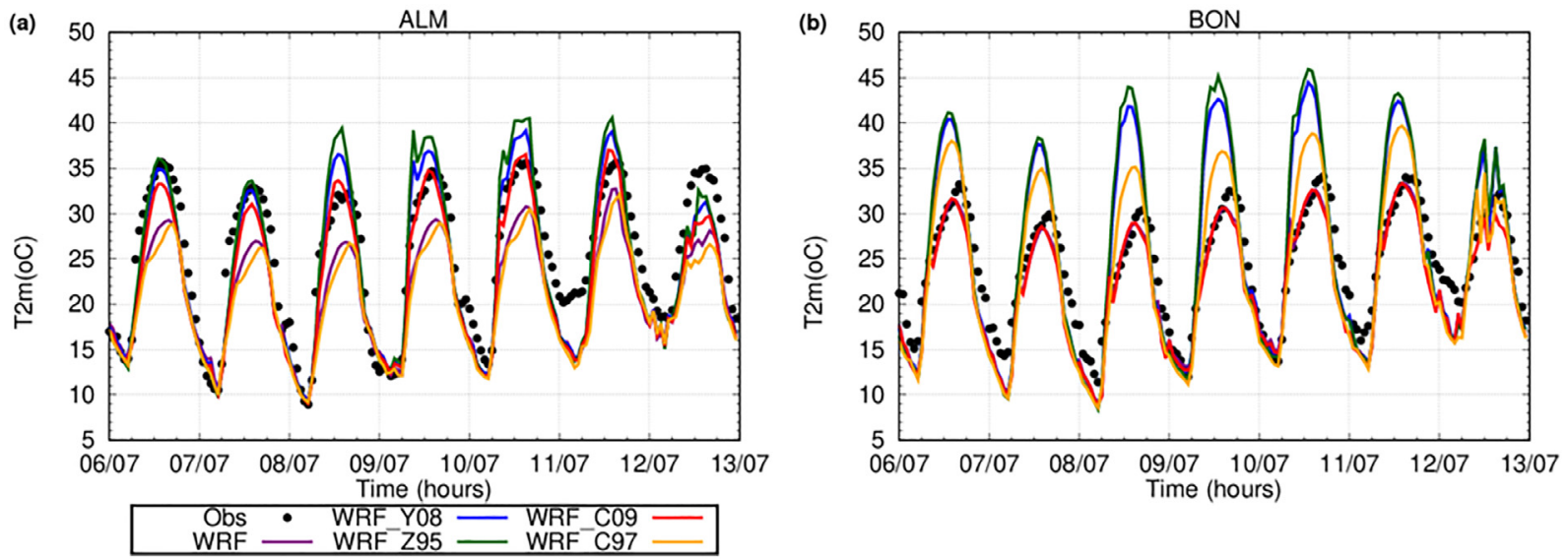

Fig. 7. Same as Fig. 6, but considering the WRF model simulations.

midpoint of the first soil layer temperatures (Milovac et al., 2016) as well as to the thermal conductivity. In the current study, no significant differences for the midpoint of the first soil layer temperatures are found using the different WRF simulations. However, relevant differences are found in terms of skin temperature (Fig. 10).

On the contrary, Y08 scheme includes $t_{*}$ together with $\mathrm{u}_{*}$ to define $\mathrm{z}_{\mathrm{oh}}$. In this case, slightly larger sensible heat flux values are obtained compared to those simulated using Z95, thus producing slightly lower skin temperatures. Comparing the surface exchange coefficient for heat $\left(\mathrm{C}_{\mathrm{h}}\right)$ simulated by WRF_Z95 and WRF_Y08 (Fig. 11), maximum

(a) ALM

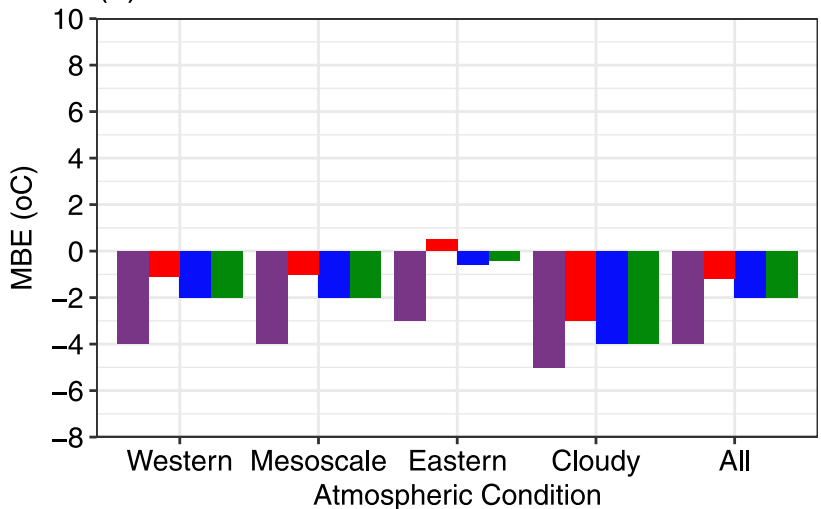

(c) BON

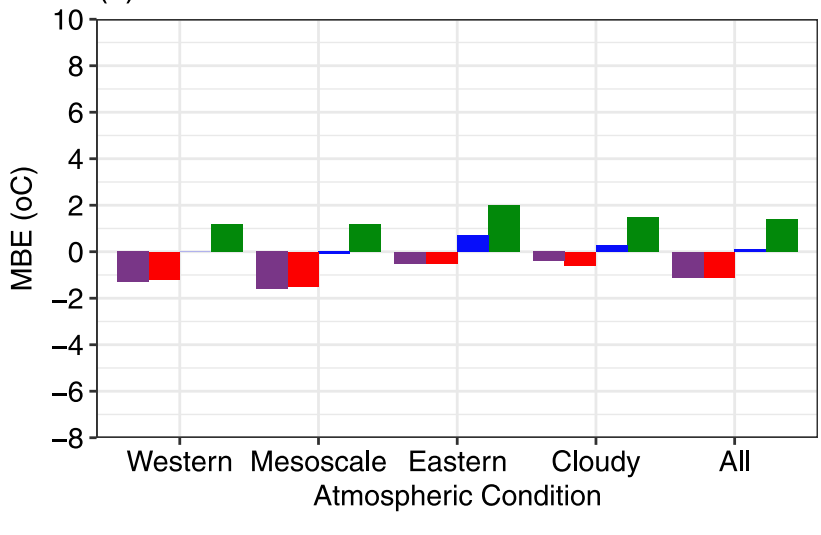

RAMS

differences around 0.003 and 0.004 are found over BON and ALM, respectively, with slightly larger values in the case of WRF_Y08. The definition of $\mathrm{z}_{0 \mathrm{~h}}$ according to Y08 leads to higher values of this parameter than those obtained using $\mathrm{Z95}$, where the $t_{*}$ parameter is not used.

Based on these results, it seems that an excess resistance, such as that included in Eq. (3), must be introduced in Eq. (1) so as to estimate the sensible heat flux based on the corresponding temperature difference (Verhoef et al., 1997). This extra resistance is crucial in order to reproduce temperatures and energy fluxes simultaneously (Yang et al.,

(b) ALM

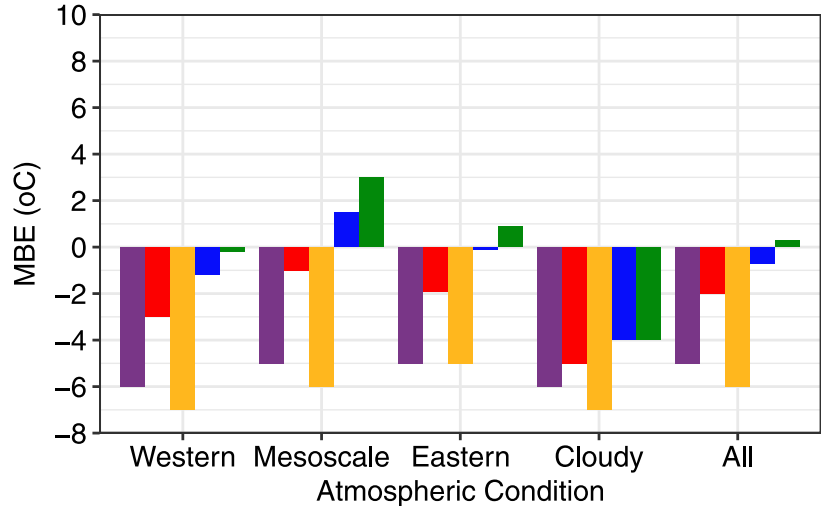

(d) BON

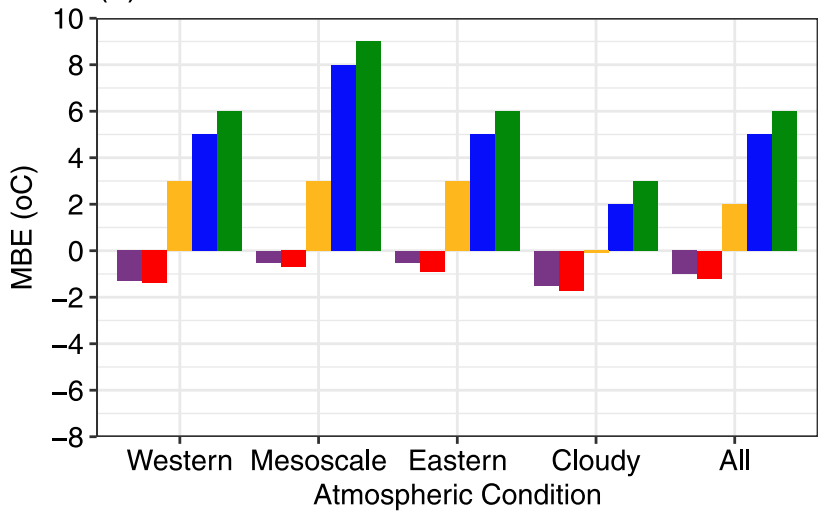

WRF WRF C09 WRF_C97 WRF_Y08 WRF_Z9

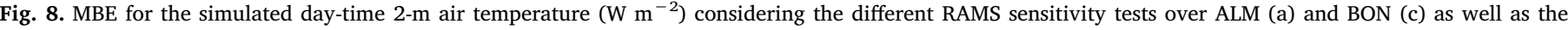
different WRF sensitivity tests over ALM (b) and BON (d), under distinct atmospheric conditions. 

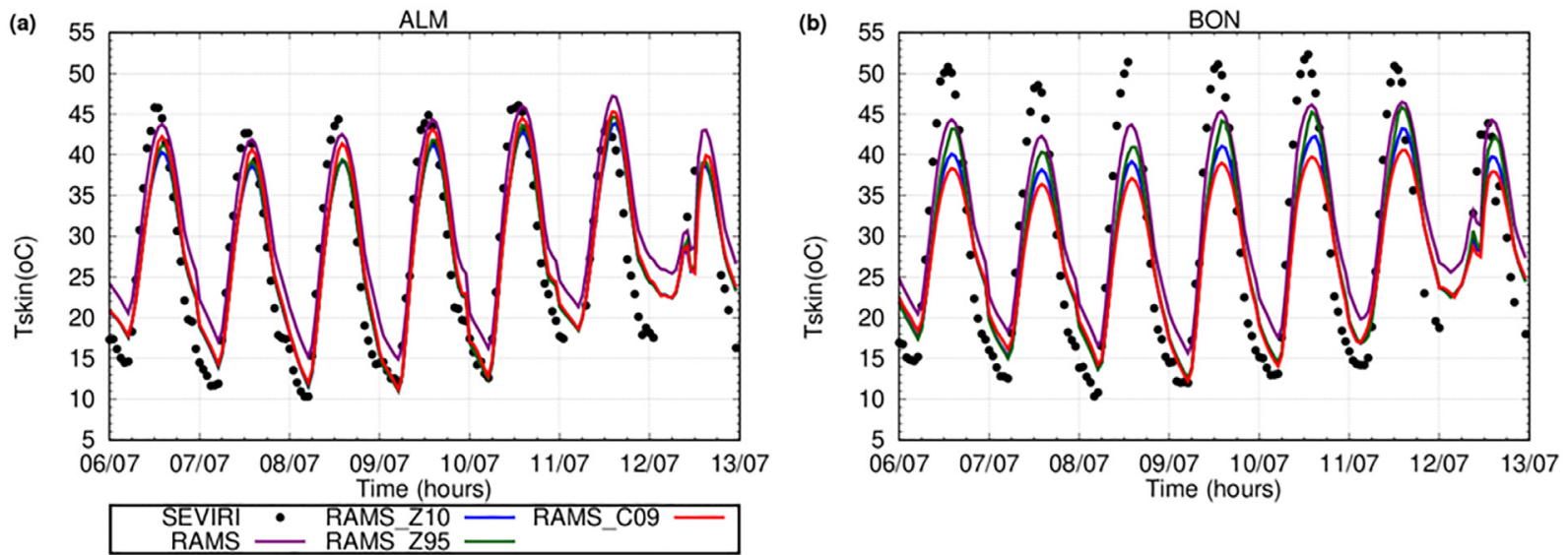

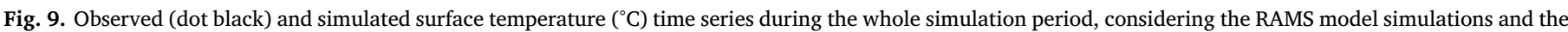
two FLUXNET stations: ALM (a) and BON (b).

2009). The current study is in agreement with these statements. For instance, the trends found here are similar to those obtained by Yang et al. (2009) applied to the Tibetan Plateau. They already pointed out that an excess resistance in the modelling better simulated the observations in comparison to not including this term. This extra resistance increased the ground-air temperature difference by means of a reduction in the simulated sensible heat flux and an increased surface temperature, as found in the current study as well. Higher surface temperatures would be directly related to higher ground soil heat fluxes and to reduced sensible heat fluxes, as mentioned above. Similar outcomes were pointed out in this sense by Chen et al. (2010), where they showed that $C_{h}$ is very sensitive to $z_{0 h}$ parameterization in arid regions. In their case, Y08 produced skin temperatures and sensible heat fluxes closer to observations than Z95. They found larger $C_{h}$ values in Z95 than Y08 as well, producing higher sensible heat fluxes and lower skin temperatures and ground soil heat fluxes. However, their results were based on a value of $\mathrm{C}_{\mathrm{zil}}=0.075$. The differences between the results obtained by Chen et al. (2010) and those shown here (Fig. 11) seem to be related to the specific $\mathrm{C}_{\mathrm{zil}}$ value used. In fact, considering $\mathrm{C}_{\mathrm{zil}}=0.01$ (strong coupling) in the current study, larger $\mathrm{C}_{\mathrm{h}}$ values are obtained compared to those simulated when $\mathrm{C}_{\mathrm{zil}}=1.0$ (weak coupling; Fig. 11) is used in $\mathrm{Z} 95$ or the Y08 is applied to the surface-layer parameterization (not shown). This seems to be consistent with the outcomes produced by Chen et al. (2010).

Using equation (15) in Niu et al. (2011) for the parameterization of the surface exchange coefficient (C97), WRF_C97 produces in general the lowest $C_{h}$ values among all WRF simulations on 6 and 7 July. This result explains the lowest heat fluxes obtained these days in Fig. 4. As a summary, considering WRF_Z95, WRF_Y08 and WRF_C97 (Fig. 11), it seems that the low $\mathrm{C}_{\mathrm{h}}$ obtained using these simulations in comparison to the original one (WRF) are the responsible for the differences found in terms of sensible heat fluxes and temperatures according to the physics incorporated to the formulations included in Section 2.3.

WRF_C09 produces slightly lower $\mathrm{C}_{\mathrm{h}}$ values than WRF over BON (Fig. 11), with maximum differences around 0.008. It could explain why lower differences are obtained between these two simulations over this weather station in comparison to the other WRF runs in terms of both temperature (Figs. 7 and 10) and sensible heat flux (Fig. 4). On the contrary, larger differences are obtained over ALM in terms of $C_{h}$ between WRF_C09 and WRF simulations in comparison to BON, with maximum differences of this parameter around 0.02-0.03 (Fig. 11). Considering these differences between WRF_C09 and WRF in terms of $\mathrm{C}_{\mathrm{h}}$ over BON and ALM, relative differences higher than $60-70 \%$ are obtained comparing these two weather stations.

Considering the RAMS simulations, it could appear that RAMS is less sensitive to $\mathrm{z}_{0 \mathrm{~h}}$ formulations than WRF (Fig. 3). However, RAMS_Z95 uses a $C_{\text {zil }}$ value of 0.06 , closer to a strong coupling, while $\mathrm{C}_{\mathrm{zil}}=1.0$ is used in the case of WRF_Z95, corresponding to a weak coupling (small $\mathrm{z}_{\mathrm{Oh}}$ ). As mentioned before, Chen et al. (2010) used a value of $\mathrm{C}_{\mathrm{zil}}=0.075$ in their study in arid and semi-arid regions. The application of $\mathrm{Z} 95$ within RAMS using $\mathrm{C}_{\mathrm{zil}}=0.01$ leads to $\mathrm{kB}^{-1}$ maximum values around 0.7 over BON and 0.5 over ALM, similar to those obtained using the original RAMS simulation (not shown). Nevertheless, using the same expression with $\mathrm{C}_{\mathrm{zil}}=0.1$ leads to maximum values around 7 and 5 over BON and ALM, respectively, thus producing higher 2-m air day-time temperatures and sensible heat fluxes than
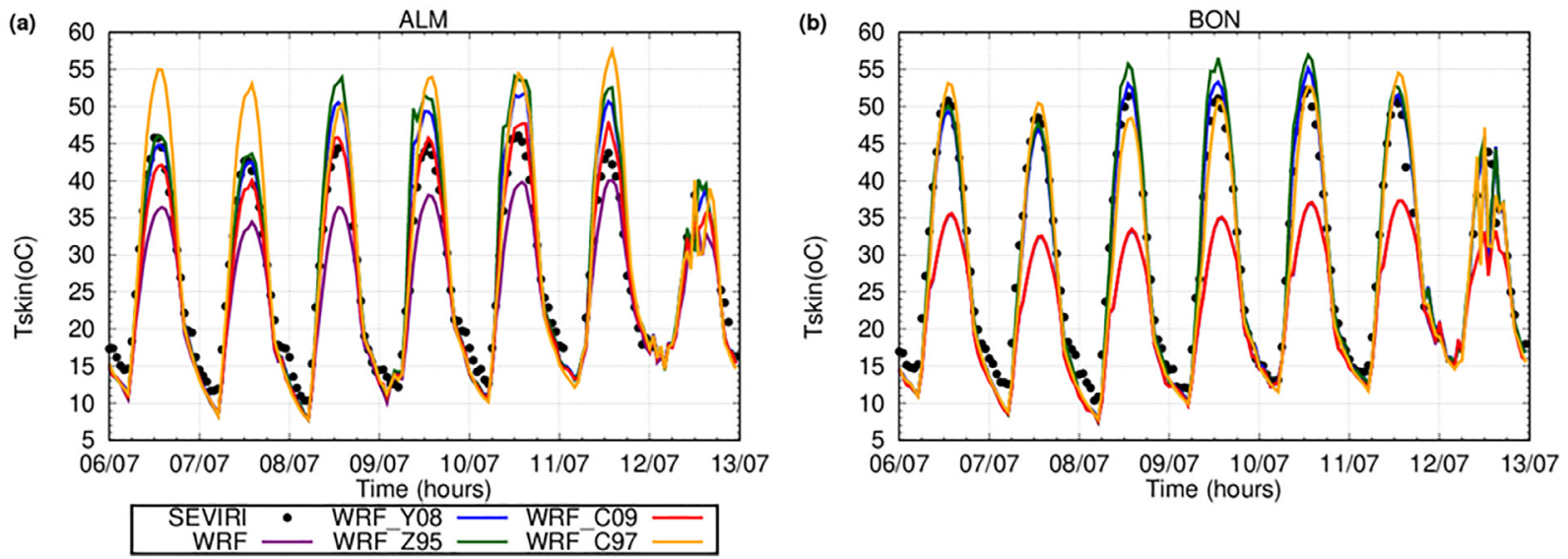

Fig. 10. Same as Fig. 9, but considering the WRF model simulations. 
(a)

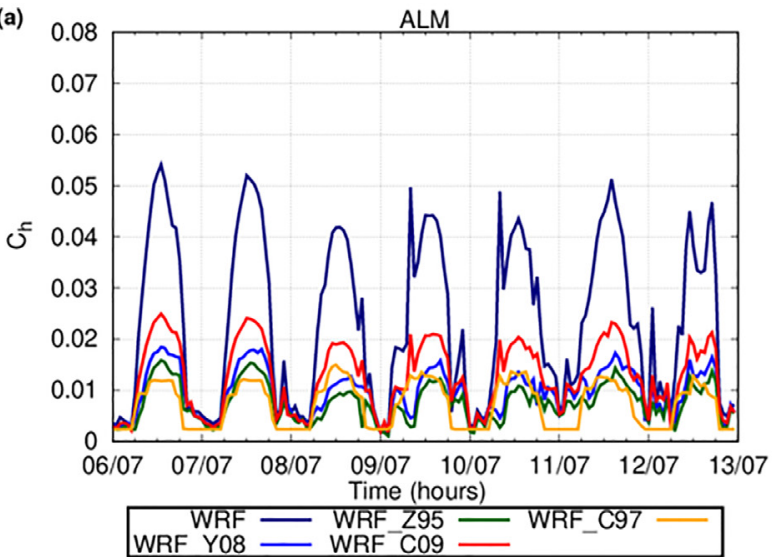

(b)

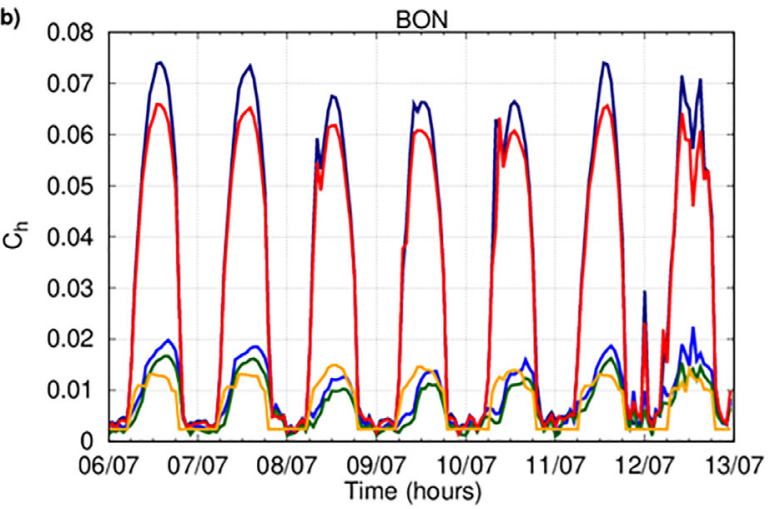

Fig. 11. WRF-simulated surface exchange coefficient for heat $\left(C_{h}\right)$ over ALM (a) and BON (b) considering the complete period of study.

(a)

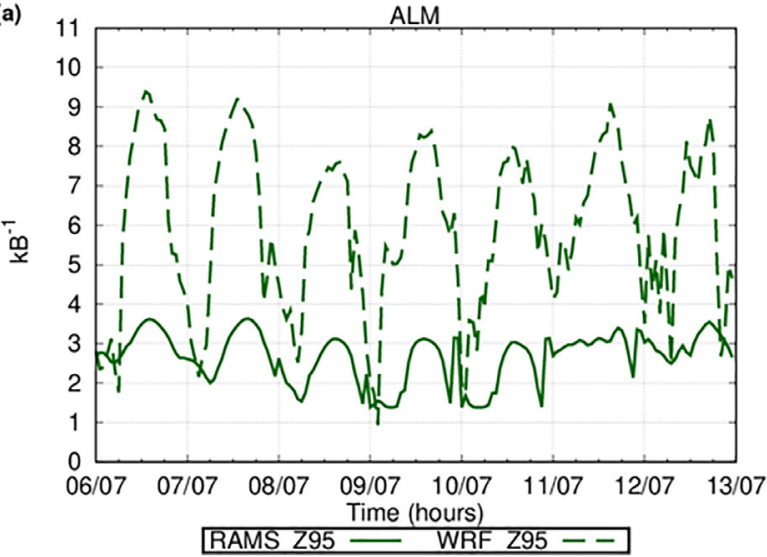

(b)

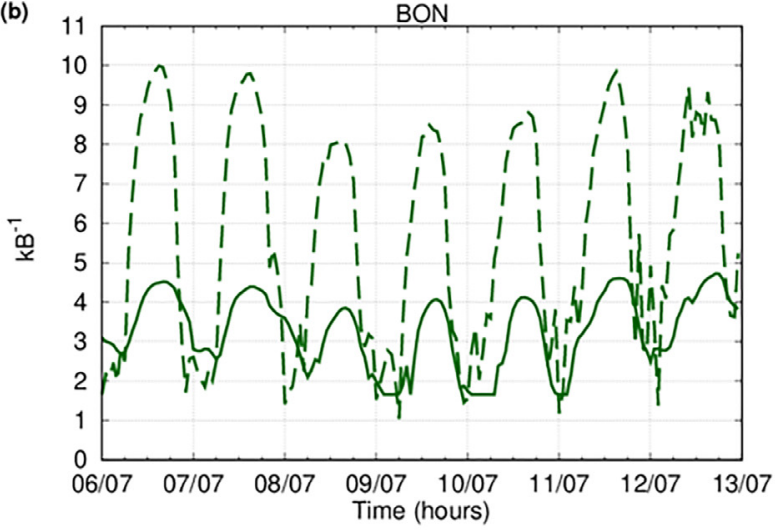

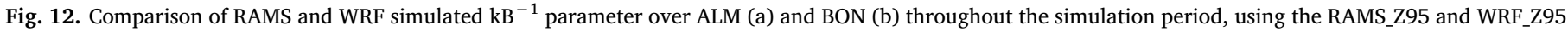
sensitivity tests.

(a)

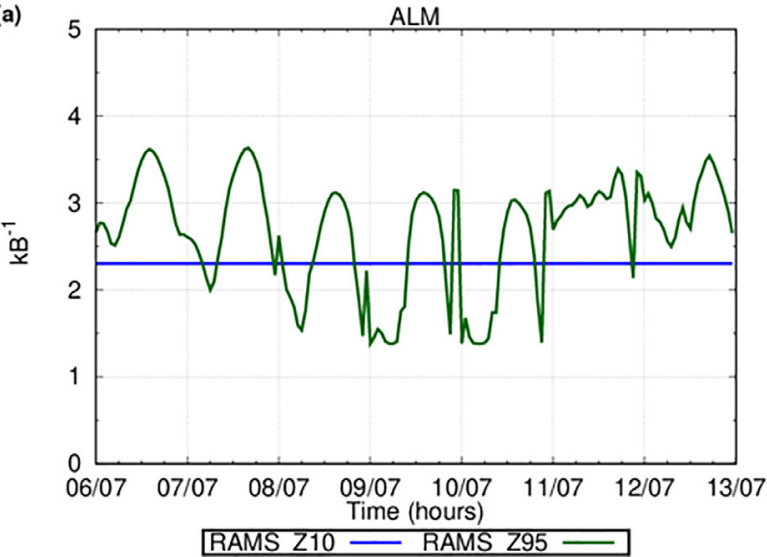

(b)

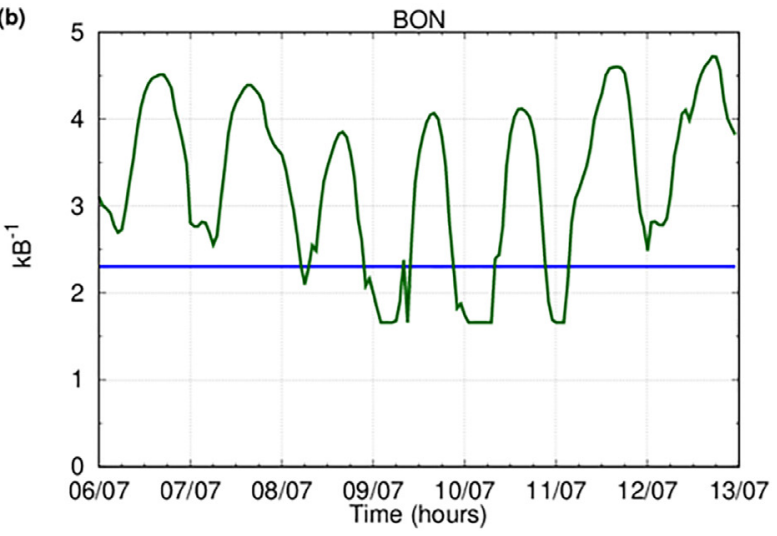

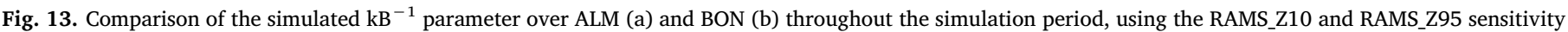
tests.

RAMS Z95. A C $\mathrm{C}_{\mathrm{zil}}$ value of 0.06 in $\mathrm{Z} 95$ for RAMS leads to $\mathrm{kB}^{-1}$ maximum values around 4 and 3 over BON and ALM, respectively (Fig. 12). This intermediate value in the $\mathrm{C}_{\mathrm{zil}}$ parameter seems to produce better results in terms of the RAMS-simulated temperatures over ALM, while it overestimates the 2-m air temperature over BON. Comparing the $\mathrm{kB}^{-1}$ term simulated by RAMS with that simulated by WRF, differences around 4-5 arise (Fig. 12). RAMS_C09 is similar to RAMS over BON, as it has been previously described for WRF, producing comparable results to RAMS_Z95 configured with a strong coupling. This result agrees with that found by Kalverla et al. (2016) using the WRF model, where a canopy-dependent parameterization for $\mathrm{C}_{\text {zil }}$ (C09) produced similar results to those obtained using $\mathrm{C}_{\mathrm{zil}}=0.01$ (strong coupling; Z95). In contrast, a weak coupling applied to RAMS remarkably overestimates the simulation of the day-time 2-m air temperature (not shown). It seems that the surface-layer parameterizations used in the current study produces indeed the same effect no matter the specific LSM formulation implemented within RAMS and WRF. However, the same surface-layer formulation for these models produces higher 2-m air temperatures 
using RAMS than those simulated using WRF (Gómez et al., 2018b). This result is obtained no matter whether $\mathrm{z}_{0 \mathrm{~h}}=\mathrm{z}_{0}$ or an alternative definition for $\mathrm{z}_{\mathrm{Oh}}$ is used. Even though both models are based on similar general physics within the corresponding LSM models, as in Eq. (1), the specific formulation of LEAF-3 and Noah-MP is different, as can be seen in Walko et al. (2000) and Niu et al. (2011), respectively.

Considering the RAMS_Z10 simulation, the value of $\mathrm{kB}^{-1}$ is around 2.3, higher than that obtained for RAMS but lower than the one simulated by RAMS_Z95. Since the only change in RAMS_Z10 in relation to RAMS is the $\mathrm{kB}^{-1}$ term, the differences shown in Fig. 6 should be related to this issue. In fact, the maximum difference of this term between RAMS_Z10 and RAMS_Z95 takes higher values over BON than over ALM (Fig. 13). The lowest differences between these two simulations over ALM in terms of the $\mathrm{kB}^{-1}$ parameter are linked to the slightly differences in the sensible heat flux and temperatures (Figs. 3a and 6a). In contrast, higher differences in the $\mathrm{kB}^{-1}$ parameter over BON lead to increased differences (Figs. $3 \mathrm{~b}$ and $6 \mathrm{~b}$ ).

Chen and Zhang (2009) found that the Noah LSM model overestimates $\mathrm{C}_{\mathrm{h}}$ for short vegetation such as grass, shrubs, and crops, indicating a too efficient coupling for short canopy. In contrast, they found that this LSM model still underestimates the coupling strength for forested regions, thus producing an insufficient coupling for tall canopy. Considering the results found in the current study, a weak coupling $\left(C_{\mathrm{zil}}=1.0\right)$, as expected in a short vegetation location such as $\mathrm{BON}$, leads to a better representation of the surface temperature but with a significant overestimation of the 2-m temperature. Therefore, both Noah and LEAF-3 seem to be too efficiently coupled to the corresponding atmospheric model and a overly strong land-atmosphere feedback is obtained over poor and sparsely vegetated regions. On the contrary, a strong coupling (lowest $\mathrm{C}_{\mathrm{zil}}$ values), as expected in a tall and well-vegetated area of a forest area such as ALM, may underestimate the coupling strength, thus producing lower temperatures than observed. However, assigning different $\mathrm{C}_{\mathrm{zil}}$ values in Zilitinkevich's formulation to define the coupling strength leads to more adjusted simulation results over tall and well-vegetated forested regions.

Regarding the results obtained using the $\mathrm{C} 09$ parameterization for the thermal roughness length, it must be noted here that the canopy height formulation proposed by Chen and Zhang (2009) was specified for the Noah LSM. In the current study, the multiparameterization options of this LSM (Noah-MP) is used, and defining $\mathrm{z}_{0}$ as $7 \%$ of the canopy height seems to be good choice using WRF (Fig. 7). However, the same formulation applied to LEAF-3, as implemented in RAMS, produces an overestimation of the day-time 2-m temperature over ALM (Fig. 6). In this mentioned study, assigning distinct $\mathrm{C}_{\mathrm{zil}}$ values for different vegetation covers in Zilitinkevich's formulation (Z95 and C09) allowed the Noah LSM to properly capture the observed $C_{h}$. Y08 and a strong coupling in Z95 produce extremely high temperatures over the area of study. Thus, these simulations do not produce a general improvement to the model performance. In contrast, the incorporation of the canopy height, such as in Chen and Zhang (2009), seems to be of significant importance to properly determine the coupling strength in the surface-layer scheme formulation. For instance, defining the $\mathrm{C}_{\mathrm{zil}}$ parameter based on the $\mathrm{C} 09$ relationship can improve the modelling results when different land uses and vegetation covers are present within the simulation area.

A differential treatment for the momentum and thermal roughness lengths may improve the forecast of the temperature field. This differential treatment in the roughness lengths is more important over tall vegetation areas, such as ALM in the current study. In addition, it depends on the dominant atmospheric condition over the area of study. This issue was already pointed out by Anurose and Subrahamanyam (2014). They found that the predictability of the sensible heat flux with different momentum and thermal roughness lengths produces a better accuracy under clear-sky and cloudy conditions, but does not produce significant variations for rainy days. Although the atmospheric situation over the area of study is based on the wind field in the current study, it seems that this point should also be taking into account. Additionally, Anurose and Subrahamanyam (2013, 2014) modified the original L79 scheme by using a momentum to thermal roughness length ratio of $100, \mathrm{kB}^{-1}$ around 4.6 , over an heterogeneous terrain centred around Thiruvananthapuram, a coastal station in India. Although they found that this approach produced significant improvements, this is not the case over the area of study tackled in the current study. It is necessary to use momentum to thermal roughness length ratios near 10 so as to properly reproduce the observed temperature field over ALM (Fig. 6a). Nevertheless, the value finally adapted in the current study is similar to the momentum to thermal roughness length ratio previously used over forested areas (Sánchez et al., 2009).

\section{Summary and conclusion}

The current study evaluates the ability of two state-of-the-art atmospheric models, RAMS and WRF, to forecast the surface heat fluxes as well as the temperature field over two very different land uses and vegetated covers, one corresponding to a poor and sparsely vegetated area and the other one corresponding to a well and tall vegetation area.

Comparing modelled and observed surface heat fluxes, RAMS appears in general to underestimate observations. Additionally, WRF also underestimates the sensible heat fluxes using WRF_Z95, WRF_Y08 and WRF_C97, whereas WRF and WRF_C09 shows in general the opposite trend. RAMS produces lower sensible heat fluxes than WRF for both vegetation covers. Moreover, RAMS and WRF simulate lower 2-m temperatures than observed over the two distinct vegetation covers during the day. However, the differences between the observations and the modelling results is clearly reduced over the poor and sparsely vegetated location, while larger differences are found over the well and tall vegetation location.

Modifications in the surface-layer scheme implemented in the corresponding LSM model does not produce any relevant improvement of the model's performance over poor and sparsely vegetated areas. This should be expected as small roughness lengths are obtained over these locations. However, atmosphere-surface coupling strength plays a relevant role over forested regions. In this case, a differential treatment of $\mathrm{z}_{0}$ and $\mathrm{z}_{\mathrm{Oh}}$ in the surface-layer scheme leads to remarkably improved results in terms of temperature as well as in the sensible heat flux, removing the original cold bias in the $2-\mathrm{m}$ temperature.

Considering the studied surface-layer parameterization, we found that large differences occur under clear-sky conditions. However, the application of the surface-layer parameterization under cloudy conditions does not produce meaningful differences compared to the results obtained when the original scheme is maintained. Comparing RAMS and WRF with the observations, both models produces the largest differences under cloudy conditions considering all simulation results.

Finally, using a surface-layer parameterization based on the canopy height reasonably reproduces the observations in general, as forested and tall and well vegetated areas are better represented with no detrimental of the skilled results obtained over poor and sparsely vegetated areas. In this regard, WRF_C09 seems to be a skilful choice to properly represent the sensible heat flux and the temperature field under mesoscale circulations over ALM. Additionally, RAMS_Z10 and RAMS_Z95 simulations seem skilful choices to properly represent the sensible heat flux and the temperature field over this weather station location, thus improving the results obtained in previous studies using RAMS (Gómez et al., 2018a).

\section{Acknowledgements}

This work has been funded by the Regional Government of Valencia through the project PROMETEOII/2014/086 and by the Spanish Ministerio de Economía y Competitividad and the European Regional Development Fund (FEDER) through the project CGL2015-64268-R 
(MINECO/FEDER,UE). We would like to thank Dr. Eva Rubio, from the University of Castilla-La Mancha - Applied Physics Department, for her careful providing of the observational datasets used in the current study. NCEP is acknowledged for providing the FNL analysis data for RAMS and WRF initialization. National Centers for Environmental Prediction/National Weather Service/NOAA/U.S. Department of Commerce (2000): NCEP FNL Operational Model Global Tropospheric Analyses, continuing from July 1999. Research Data Archive at the National Center for Atmospheric Research, Computational and Information Systems Laboratory. Dataset. http://rda.ucar.edu/ datasets/ds083.2. Accessed 25 August 2014.

\section{References}

Anurose, T.J., Subrahamanyam, D.B., 2013. Improvements in sensible heat-flux parametrization in the high-resolution regional model (HRM) through the modified treatment of the roughness length for heat. Bound.-Lay. Meteorol. 147 (3), 569-578. https://doi.org/10.1007/s10546-013-9799-9.

Anurose, T.J., Subrahamanyam, D.B., 2014. Assessment of a surface-layer parameterization scheme in an atmospheric model for varying meteorological conditions. Ann. Geophys. 32, 669-675. https://doi.org/10.5194/angeo-32-669-2014. 2014.

Beljaars, A.C.M., Holtslag, A.A.M., 1991. Flux parameterization over land surface for atmospheric models. J. Appl. Meteorol. 30, 327-341. https://doi.org/10.1175/15200450(1991) $030<0327$ :FPOLSF $>2.0$. CO; 2 .

Brutsaert, W., 1975. The roughness length for water vapor sensible heat, and other scalars. J. Atmos. Sci. 32, 2028-2031. https://doi.org/10.1175/1520-0469(1975) $032<2029$ :TRLFWV $>2.0$. CO; 2 .

Caselles, V., Valor, E., Coll, C., Rubio, E., 1997. Thermal band selection for the prism instrument: 1 . analysis of emissivity-temperature separation algorithms. J. Geophys. Res. 102 (D10), 11145-11164. https://doi.org/10.1029/97JD00344.

Castro, C., Cheng, W., Beltrán, A., Marshall Jr., C., Pielke Sr., R., Cotton, W., 2002. The incorporation of the Kain-Fritsch cumulus parameterization scheme in RAMS with a terrain-adjusted trigger function. In: Fifth RAMS Users Workshop, Santorini Island. Greece, 29 September-October 3, 2002.

Chen, C., Cotton, W.R., 1983. A one-dimensional simulation of the stratocumulus-capped mixed layer. Bound.-Lay. Meteorol. 25, 289-321. https://doi.org/10.1007/ BF00119541.

Chen, F., Janjic, Z., Mitchell, K., 1997. Impact of atmospheric surface-layer parameterizations in the new land-surface scheme of the NCEP mesoscale eta model. Bound.-Lay. Meteorol. 85, 391-421. https://doi.org/10.1023/A:1000531001463.

Chen, F., Zhang, Y., 2009. On the coupling strength between the land surface and the atmosphere: from viewpoint of surface exchange coefficients. Geophys. Res. Lett. 36, L10404. https://doi.org/10.1029/2009GL037980.

Chen, Y., Yang, K., Zhou, D., Qin, J., Guo, X., 2010. Improving the Noah land surface model in arid regions with an appropriate parameterization of the thermal roughness length. J. Hydrometeor. 11, 995-1006. https://doi.org/10.1175/2010JHM1185.1.

Cotton, W.R., Pielke, R.A.S., Walko, R.L., Liston, G.E., Tremback, C.J., Jiang, H., McAnelly, R.L., Harrington, J.Y., Nicholls, M.E., Carrio, G.G., McFadden, J.P., 2003. RAMS 2001: current status and future directions. Meteorol. Atmos. Phys. 82 (1-4), 5-29. https://doi.org/10.1007/s00703-001-0584-9.

Dudhia, J., 1989. Numerical study of convection observed during the winter monsoon experiment using a mesoscale two-dimensional model. J. Atmos. Sci. 46, 3077-3107. https://doi.org/10.1175/1520-0469(1989)046 < 3077:NSOCOD > 2.0.CO;2.

FAO (1988). FAO/UNESCO soil map of the World, revised legend,with corrections and updates. Reprinted with Updates as Technical Paper 20, ISRIC, Wageningen, Netherlands, 1997. ()

Garratt, J.R., 1992. The Atmospheric Boundary Layer. Cambridge University Press, Cambridge, pp. 316

Gómez, I., Caselles, V., Estrela, M.J., 2015. Impacts of soil moisture content on simulated mesoscale circulations during the summer over eastern Spain. Atmos. Res. 164-165, 9-26. https://doi.org/10.1016/j.atmosres.2015.04.015.

Gómez, I., Ronda, R.J., Caselles, V., Estrela, M.J., 2016a. Implementation of non-local boundary layer schemes in the regional atmospheric modeling system and its impact on simulated mesoscale circulations. Atmos. Res. 180, 24-41. https://doi.org/10. 1016/j.atmosres.2016.04.020.

Gómez, I., Caselles, V., Estrela, M.J., Niclòs, R., 2016b. Impact of initial soil temperature derived from remote sensing and numerical weather prediction datasets on the simulation of extreme heat events. Remote Sens. 8, 589. https://doi.org/10.3390/ rs8070589.

Gómez, I., Caselles, V., Estrela, M.J., Sánchez, J.M., Rubio, E., 2018a. Simulation of surface energy fluxes and meteorological variables using the regional atmospheric modeling system (RAMS): evaluating the impact of land-atmosphere coupling on short-term forecasts. Agric. For. Meteorol. 249, 319-334. https://doi.org/10.1016/j. agrformet.2017.10.027.

Gómez, I., Caselles, V., Estrela, M.J., Miró, J.J., 2018b. Comparative assessment of RAMS and WRF short-term forecasts over Eastern Iberian Peninsula using various in-situ observations, remote sensing products and uncoupled land surface model datasets. Atmos. Res. 213, 476-491. https://doi.org/10.1016/j.atmosres.2018.06.022.

Gómez, I., Caselles, V., Estrela, Sánchez, J.M., Rubio, E., Miró, J.J., 2018c. Improved meteorology and surface fluxes in mesoscale modelling using adjusted initial vertical soil moisture profiles. Atmos. Res. 213, 523-536. https://doi.org/10.1016/j. atmosres.2018.06.020.

Hong, S., Noh, Y., Dudhia, J., 2006. A new vertical diffusion package with an explicit treatment of entrainment processes. Mon. Wea. Rev. 134 (9), 2318-2341. https:// doi.org/10.1175/MWR3199.1.

Hopwood, W.P., 1995. Surface transfer of heat and momentum over an inhomogeneous vegetated land. Q. J. Roy. Meteorol. Soc. 121, 1549-1574. https://doi.org/10.1002/ qj. 49712152704.

Kain, J.S., 2004. The Kain-Fritsch convective parameterization: an update. J. Appl. Meteor. 43, 170-181. https://doi.org/10.1175/1520-0450(2004) $043<0170$ :TKCPAU > 2.0.CO;2.

Kalverla, P., Duine, G., Steeneveld, G., Hedde, T., 2016. Evaluation of the weather research and forecasting model in the durance valley complex terrain during the kascade field campaign. J. Appl. Meteor. Climatol. 55, 861-882. https://doi.org/10. 1175/JAMC-D-15-0258.1.

López-Serrano, F.R., Rubio, E., Dadi, T., Moya, D., Andrés-Abellán, M., García-Morote, F.A., Miettinen, H., Martínez-García, E., 2016. Influences of recovery from wildfire and thinning on soil respiration of a mediterranean mixed forest. Sci. Total Environ. 573, 1217-1231. https://doi.org/10.1016/j.scitotenv.2016.03.242.

Louis, J.F., 1979. A parametric model of vertical eddy fluxes in the atmosphere. Bound. Lay. Meteorol. 17, 187-202. https://doi.org/10.1007/BF00117978.

Mahrt, L., 1996. The bulk aerodynamic formulation over heterogeneous surfaces. Bound Lay. Meteorol. 78, 87-119. https://doi.org/10.1007/BF00122488.

Milovac, J., Warrach-Sagi, K., Behrendt, A., Späth, F., Ingwersen, J., Wulfmeyer, V., 2016 Investigation of PBL schemes combining the WRF model simulations with scanning water vapor differential absorption lidar measurements. J. Geophys. Res. Atmos. 121, 624-649. https://doi.org/10.1002/2015JD023927.

Mlawer, E., Taubman, S., Brown, P., Iacono, M., Clough, S., 1997. Radiative transfer for inhomogeneous atmospheres: RRTM, a validated correlated-k model for the long wave. J. Geophys. Res. 102 (D14), 16663-16682. https://doi.org/10.1029/ 97JD00237.

Niu, G.-.Y., Yang, Z.-.L., Mitchell, K.E., Chen, F., Ek, M.B., Barlage, M., Kumar, A., Manning, K., Niyogi, D., Rosero, E., Tewari, M., Xia, Y., 2011. The community Noah land surface model with multiparameterization options (Noah-MP): 1. Model description and evaluation with local-scale measurements. J. Geophys. Res. 116 D12109. https://doi.org/10.1029/2010JD015139.

Mauder, M., Liebethal, C., Göckede, M., Leps, J.-.P., Beyrich, F., Foken, T., 2006. Processing and quality control of flux data during LITFASS-2003. Bound.-Lay. Meteorol. 121, 67-88. https://doi.org/10.1007/s10546-006-9094-0.

Pielke Sr., R.A., 2013. Mesoscale Meteorological Modeling, 3rd ed. Academic Press, San Diego, CA, pp. 760

Powers, J.G., Klemp, J.B., Skamarock, W.C., Davis, C.A., Dudhia, J., Gill, D.O., Coen, J.L., Gochis, D.J., Ahmadov, R., Peckham, S.E., Grell, G.A., Michalakes, J., Trahan, S., Benjamin, S.G., Alexander, C.R., Dimego, G.J., Wang, W., Schwartz, C.S., Romine, G.S., Liu, Z., Snyder, C., Chen, F., Barlage, M.J., Yu, W., Duda, M.G., 2017. The weather research and forecasting model: overview, system efforts, and future directions. B. Am. Meteorol. Soc. 98, 1717-1737. https://doi.org/10.1175/BAMS-D-1500308.1.

Sánchez, J.M., Caselles, V., Niclòs, R., Coll, C., Kustas, W.P., 2009. Estimating energy balance fluxes above a boreal forest from radiometric temperature observations. Agric. For. Meteorol. 149, 1037-1049. https://doi.org/10.1016/j.agrformet.2008.12. 009 .

Skamarock, W.C., Klemp, J.B., Dudhia, J., Gill, D.O., Barker, D.M., Duda, M.G., Huang, X.Y., Wang, W., Powers, J.G., 2008. A Description of the Advanced Research WRF Version 3. NCAR Technical Note, NCAR/TN-475 + STR. Mesoscale and Microscale Meteorology Division, National Center for Atmospheric Research, Boulder, CO, USA.

Song, Y., 1998. An improvement of the Louis scheme for the surface layer in an atmospheric modelling system. Bound.-Lay. Meteorol. 88, 239-254. https://doi.org/10. 1023/A:1001119329423.

Steeneveld, G.J., Tolk, L.F., Moene, A.F., Hartogensis, O.K., Peters, W., Holtslag, A.A.M., 2011. Confronting the WRF and RAMS mesoscale models with innovative observations in the Netherlands: evaluating the boundary layer heat budget. J. Geophys. Res. Atmos. 116 (D23), D23114.

Stewart, J.B., Kustas, W.P., Humes, K.S., Nichols, W.D., Moran, M.S., de Bruin, H.A., 1994. Sensible heat flux-radiometric surface temperature relationship for eight semiarid areas. J. Appl. Meteor. 33, 1110-1117. https://doi.org/10.1175/15200450(1994)033<1110:SHFRST > 2.0.CO;2.

Sun, J., 1999. Diurnal variations of thermal roughness height over a grassland. Bound.Lay. Meteor. 92, 407-427. https://doi.org/10.1023/A:1002071421362.

Trigo, I.F., Monteiro, I.T., Olesen, F., Kabsch, E., 2008. An assessment of remotely sensed land surface temperature. J. Geophys. Res. 113, D17108. https://doi.org/10.1029/ 2008JD010035.

Verhoef, A., de Bruin, H.A.R., van den Hurk, B.J.J.M., 1997. Some practical notes on the parameter kB 21 for sparse vegetation. J. Appl. Meteor. 36, 560-572. https://doi. org/10.1175/1520-0450(1997)036<0560:SPNOTP > 2.0.CO;2.

Walko, R.L., Band, L.E., Baron, J., Kittel, T.G.F., Lammers, R., Lee, T.J., Ojima, D., Pielke, R.A., Taylor, C., Tague, C., Tremback, C.J., Vidale, P.L., 2000. Coupled atmospheric biophysics-hydrology models for environmental modeling. J. Appl. Meteorol. 39, 931-944. https://doi.org/10.1175/1520-0450(2000)039<0931:CABHMF $>2.0$. $\mathrm{CO} ; 2$.

Yang, K., Koike, T., Ishikawa, H., Kim, J., Li, X., Liu, H., Liu, S., Ma, Y., Wang, J., 2008 Turbulent flux transfer over bare-soil surfaces: characteristics and parameterization. J. Appl. Meteor. Climatol. 47, 276-290. https://doi.org/10.1175/2007JAMC1547.1.

Yang, K., Chen, Y.-.Y., Qin, J., 2009. Some practical notes on the land surface modeling in the Tibetan Plateau. Hydrol. Earth Syst. Sci. 13, 687-701. https://doi.org/10.5194/ hess-13-687-2009.

Zilitinkevich, S.S., 1995. Non-local Turbulent Transport: Pollution Dispersion Aspects of Coherent Structure of Convective Flows, in Air Pollution III, vol. I, Air Pollution Theory and Simulations. In: Power, H., Moussiopoulos, N., Brebbia, C.A. (Eds.), Comput. Mech. Publ., Boston, Mass, pp. 53-60. 